\title{
Effect of Seed Size and Pretreatment Methods on Germination of Albizia lebbeck
}

\author{
Edward Missanjo, Chikumbutso Maya, Dackious Kapira, \\ Hannah Banda, and Gift Kamanga-Thole \\ Malawi College of Forestry and Wildlife, Private Bag 6, Dedza, Malawi \\ Correspondence should be addressed to Edward Missanjo; edward.em2@gmail.com
}

Received 5 June 2013; Accepted 5 July 2013

Academic Editors: P. Parolin and S. Satoh

Copyright ( 2013 Edward Missanjo et al. This is an open access article distributed under the Creative Commons Attribution License, which permits unrestricted use, distribution, and reproduction in any medium, provided the original work is properly cited.

\begin{abstract}
Albizia lebbeck is a multipurpose tree species prioritised for conservation in Malawi. The different plant parts are used in traditional medicine to treat different diseases. However, the seeds are dormant, and the tree species remain undomesticated. A study was conducted to evaluate the effect of seed size and presowing on the germination of Albizia lebbeck in a nursery. Seeds were grouped into four categories in regard to their length, small $(\leq 0.5 \mathrm{~cm})$, medium $(>0.5<0.8 \mathrm{~cm})$, large $(\geq 0.8 \mathrm{~cm})$, and mixture of small, medium, and large seeds. The seeds were subjected to five main seed pretreatment methods, namely, soaking in sulphuric acid for 2 minutes, nicking, soaking in hot water for 5 minutes, soaking in cold water for 24 hours, and control where seeds were sown without any treatment. The results indicate that combination of nicking and large seeds produced the highest (100\%) germination. Hot water treatment was effective in large seeds producing $67.5 \%$ germination. The increased germination for mechanically scarified seeds through nicking suggests that seed dormancy in Albizia lebbeck is mainly due to its hard seed coat. Therefore, it is recommended to farmers to adopt use of nicking and large seeds, since it is safe and effective.
\end{abstract}

\section{Introduction}

Albizia lebbeck is widely spread in the world, and its tree has large leaves and fragrant cluster of green-yellow flowers and long seed pods. Belonging to the family of Leguminosae [1], it is native to tropical Asia and widely cultivated and naturalized in other tropical and subtropical regions including Malawi [2, 3]. Albizia lebbeck grows to the height of $18-30 \mathrm{~m}$ with a trunk diameter of $50 \mathrm{~cm}$ to $1 \mathrm{~m}$ at maturity. The leaves are 7 to $15 \mathrm{~cm}$ long with one to four pairs of pinnae, and each pinna has 6 to 8 leaflets. The flowers are white with numerous stamens and very fragrant. The fruit pods are 15 to $30 \mathrm{~cm}$ long and 2.5 to $5.0 \mathrm{~cm}$ broad containing six to twelve seeds [4].

The flowers, bark, fruits, roots, and stems of Albizia lebbeck are all used for medicine. A paste of leaves is used to treat skin problems. Albizia lebbeck is also known for treating respiratory problems including allergies [5]. Furthermore, other parts of the plants are used to treat eye problem, purify blood, and promote health in teeth. Most importantly, ethanol extract from its pods is effective against some form of cancer [6]. The leaves are nutritious as they contain proteins, calcium, phosphorous, and amino acids [2, 4]. Albizia lebbeck is one of the most promising fodder trees. It has leaves during a large part of the rainy season, and digestibility of the twigs is considerably higher than that of most fodder trees. The concentration of crude protein is about $20 \%$ for green leaves, $13 \%$ for leaf litter, and $10 \%$ for twigs. In vitro digestibility is about $45 \%$ for mature leaves, $70 \%$ for young leaves and $40 \%$ for twigs. Leaves, flowers, and pods fall to the ground gradually during the dry season and can be browsed on the ground [3]. It is an excellent fuelwood and charcoal species, and the wood is suitable for construction, furniture, and veneer. The shallow root system makes it a good soil binder and recommendable for soil conservation and erosion control $[5,6]$.

Despite its importance, the species is becoming scarce in Malawi due to deep seed dormancy. The tree species has been given priority as one of the species for conservation in Malawi to enhance its contribution to health and livelihood of communities. From this point of view, a study was carried out 
to assess the effects of different seed pretreatment methods and seed size on germination of Albizia lebbeck.

\section{Materials and Methods}

2.1. Study Site. The study was conducted in Malawi located in Southern Africa in the tropical savanna region at Malawi College of Forestry and Wildlife (MCFW) nursery $\left(14^{\circ} 19^{\prime} \mathrm{S}\right.$, $34^{\circ} 17^{\prime} \mathrm{E}$, and $1591 \mathrm{~m}$ above sea level). MCFW receives $1200 \mathrm{~mm}$ to $1800 \mathrm{~mm}$ rainfall per annum, with annual temperature ranging from $7^{\circ} \mathrm{C}$ to $25^{\circ} \mathrm{C}$. It is situated about $85 \mathrm{~km}$ southeast of Lilongwe, the capital.

2.2. Experimental Design and Treatments. A total of 1600 seeds were directly sawn in $10 \mathrm{~cm}$ polythene tubes, and one seed was planted per tube. The seeds were subjected to twenty treatments which were completely randomised in four replicates. Each treatment had 20 seeds. The treatment combination consisted of two factors, namely, seed size and pretreatment methods. The first factor of seed size consisted of seeds of length less than $0.5 \mathrm{~cm}$ and was denoted as small; $0.51 \mathrm{~cm}$ to $0.8 \mathrm{~cm}$ seeds were considered medium; seeds of $0.8 \mathrm{~cm}$ long and greater were categorized large. A fourth seed size category was a control which consisted of three dimensions (small, large, and medium) of seeds. The second factor of pretreatment methods involved five seed pretreatment methods, namely, cold water soaking for 24 hours, hot water soaking for 5 minutes, and 2 minute immersion in concentrated sulphuric acid $\left(0.3 \mathrm{M} \mathrm{H}_{2} \mathrm{SO}_{4}\right)$, including mechanical scarification by nicking, and a fifth treatment was a control which consisted of seeds that were left intact.

\subsection{Pretreatment Procedure}

2.3.1. Cold and Hot Water Treatment. Twenty seeds from each seed size category (small, medium, large, and mixture) were put in similar beaker sizes where cold water at room temperature was poured and the seeds were soaked for 24 hours. Water was then removed and the seeds were planted on the same day. For the hot water treatment, water was heated to approximately $100^{\circ} \mathrm{C}$ and was then poured into beakers containing twenty seeds from each seed category (small, medium, large, and mixture) and was left to stand for 5 minutes after which the seeds were sown.

2.3.2. Immersion in Concentrated Sulphuric Acid. Seeds of small, medium, large, and mixture seed categories were put into separate beakers. Concentrated sulphuric acid $(0.3 \mathrm{M}$ $\mathrm{H}_{2} \mathrm{SO}_{4}$ ) was then added to the beakers each containing twenty seeds and were left to soak for 2 minutes. After immersion, the solution was drained off, and seeds were repeatedly rinsed in running tap water until considered safe to handle. Then the seeds were sown.

2.3.3. Nicking. Twenty seeds from each size category were mechanically nicked on one side away from the micropyle using secateurs and then sown immediately. Watering was done accordingly to keep the beds with adequate moisture. In total, there were twenty treatment combinations and were denoted as follows:

T1: small seeds immersed in $0.3 \mathrm{M}$ sulphuric acid $\left(\mathrm{H}_{2} \mathrm{SO}_{4}\right)$ for 2 minutes;

T2: small seeds with nicking;

T3: small seeds soaked in hot water at $100^{\circ} \mathrm{C}$ for 5 minutes;

T4: small seeds soaked in cold water at room temperature for 24 hours;

T5: small seeds sown without pretreatment;

T6: large seeds immersed in $0.3 \mathrm{M}$ sulphuric acid $\left(\mathrm{H}_{2} \mathrm{SO}_{4}\right)$ for 2 minutes;

T7: large seeds with nicking;

T8: large seeds soaked in hot water at $100^{\circ} \mathrm{C}$ for 5 minutes;

T9: large seeds soaked in cold water at room temperature for 24 hours;

T10: large seeds sown without pretreatment;

T11: medium seeds immersed in $0.3 \mathrm{M}$ sulphuric acid $\left(\mathrm{H}_{2} \mathrm{SO}_{4}\right)$ for 2 minutes;

T12: medium seeds with nicking;

T13: medium seeds soaked in hot water at $100^{\circ} \mathrm{C}$ for 5 minutes;

T14: medium seeds soaked in cold water at room temperature for 24 hours;

T15: medium seeds sown without pretreatment;

T16: mixture of seeds immersed in $0.3 \mathrm{M}$ sulphuric acid $\left(\mathrm{H}_{2} \mathrm{SO}_{4}\right)$ for 2 minutes;

T17: mixture of seeds with nicking;

T18: mixture of seeds soaked in hot water at $100^{\circ} \mathrm{C}$ for 5 minutes;

T19: mixture of seeds soaked in cold water at room temperature for 24 hours;

T20: mixture of seeds sown without pretreatment.

2.3.4. Data Collection and Analysis. Data on germination were recorded on daily basis for a period of eight weeks (56 days) from the day of sowing. Germination was defined as the emergence of radicle from the seed coat. Daily germination percentages were summed up to obtain cumulative germination for each treatment. Data obtained was subjected to analysis of variance (ANOVA) using GenStat for Windows, version 13 [7]. Differences between treatment means were separated using Fischer's least significant difference (LSD) at the 0.05 level. The data was analysed using the following model:

$$
Y_{i j k}=\mu+S_{i}+P_{j}+(S P)_{i j}+e_{i j k},
$$

where $Y_{i j k}$ is the response variable (germination percentage) of $j$ th observation in $i$ th treatments, $\mu$ is the overall mean, $S_{i}$ is the fixed effect of seed size $(i=1,2,3,4), P_{j}$ is the fixed effect of pretreatment methods $(j=1,2,3,4,5)$, 
TABLE 1: Effect of pretreatment methods and size of Albizia lebbeck seeds on germination at eight (8) weeks after sowing.

\begin{tabular}{lcccccc}
\hline \multirow{2}{*}{ Seed size } & \multicolumn{5}{c}{ Germination percentage (\%) for different presowing treatment methods } \\
& $\mathrm{H}_{2} \mathrm{SO}_{4}$ & Nicking & Hot water & Cold water & Control & Mean \\
\hline Large & 30.0 & 100 & 67.5 & 22.5 & 48.5 \\
Medium & 54.5 & 80.0 & 43.8 & 28.8 & 22.5 & 21.2 \\
Small & 49.5 & 71.2 & 55.0 & 10.0 & 20.0 & 45.7 \\
Mixture & 37.5 & 70.0 & 50.0 & 41.0 & 41.1 & 33.8 \\
Mean & $42.9^{\mathrm{b}}$ & $80.3^{\mathrm{a}}$ & $54.1^{\mathrm{b}}$ & $25.6^{\mathrm{c}}$ & $24.4^{\mathrm{c}}$ & 46.5 \\
\hline
\end{tabular}

Note. Means with different superscripts within a row differ $(P<0.001)$.

$\mathrm{SE}=0.243$.

$\mathrm{LSD}=15.7$

$\mathrm{CV}=11.1 \%$.

$(S P)_{i j}$ is the effect of the interaction between seed size and pretreatment methods, and $e_{i j k}$ is the random residual effect, $e_{i j k} \sim N\left(0, \sigma e^{2}\right)$.

\section{Results}

There were no significant $(P>0.05)$ differences in germination between seed sizes, although larger seeds had a higher germination (48.5\%) percentage followed by mixture of seeds (46.5\%) and then medium seeds (45.7\%). Small seeds had an average of $41.1 \%$ germination. However, there were significant $(P<0.001)$ differences in germination among presowing treatments where nicking gave the highest germination $(80.3 \%)$ followed by immersion in hot water (54.1\%) and then immersion in $0.3 \mathrm{M} \mathrm{H}_{2} \mathrm{SO}_{4}$ acid with $42.9 \%$ germination. The combination of nicking and large seeds produced the highest (100\%) germination followed by the combination of soaking in hot water and large seeds which produced $67.5 \%$ germination (Table 1 ).

When germination was observed over time, nicking in all the seed size category had the highest rate of germination in the first two weeks, then the rate of germination became constant. However, in hot water treatments germination increased rapidly between the first to sixth week after which it remained constant (Figure 1).

\section{Discussion}

The results were not significantly different among seed sizes. However, large seeds produced higher germination than other seed size categories. The present findings are in agreement with those reported by [8-10]. Esen et al. [11] reported that large and heavy seeds contain larger amounts of reserves to stimulate germination, seedling survival, and growth.

The results obtained in this study entail the vital role of pretreating Albizia lebbeck seeds prior to sowing for enhanced germination and domestication of the species. Germination percentage varied among different pretreatment methods. High seed germination percentage for nicked seeds suggests that this is the best method to be applied before sowing Albizia lebbeck seeds. The results reported in this study agreed to those in literature $[9,12-15]$, in which nicking has been



FIGURE 1: Effect of pretreatment methods (nicking and hot water immersion) and size of Albizia lebbeck seeds on maximum germination.

shown to enhance germination of different tropical forest tree species. Nicking has been found to be extremely effective for most species, because cracks or cuts made on the seed makes it easier for entry of water and exchange of gases resulting in enzymatic hydrolysis and thus transforming the embryo into a seedling [16-18].

Hot water treatment emerged the second best pre-sowing seed treatment method, producing higher germination percentage of $67.5 \%$ for large seeds of Albizia lebbeck. Soaking seed in hot water may soften hard seed coats, this makes the seed coats permeable to water and the seeds imbibe and swell as the water cools $[9,19]$. Likoswe et al. [15] showed that soaking seeds in hot water leaches out chemical inhibitors resulting in breakage of chemical seed dormancy.

Soaking in sulphuric acid came third with its germination percentage of $41.9 \%$. Whenever seeds are sufficiently soaked in sulphuric acid, it results into over $90 \%$ germination percentage $[4,17,19-21]$. Insufficient soaking may not be effective 
enough as it just makes the seed coat glossy. Furthermore, concentration of the acid and time of exposure are very critical and need to be quantified for each species since seeds exposed for a long time get damaged easily $[19,22]$. In this study only one concentration and time of exposure to the sulphuric acid was used.

Less effectiveness of cold water method is due to limited time of soaking. Though the seed coats were softened but the period was not enough to maximize germination percentage and reduce lengthy germination period [12, 23, 24]. Duration more than 24 hours is needed; 48 hours or more per se is required for more effective results [15].

\section{Conclusion}

Seed pretreatment methods and seed size affected the germination of Albizia lebbeck. The larger seeds resulted in higher germination percentage since larger seeds contain more food reserves to support germination. Nicking has shown to be the overall best presowing seed treatment method in Albizia lebbeck followed by hot water treatment. Therefore, this study recommends to farmers to adopt use of nicking and large seeds, since it is safe and effective.

\section{Acknowledgments}

The authors thank Mr. Anderson Ndema and his colleagues of Malawi College of Forestry and Wildlife (MCFW) for providing them with polythene tubes that were used in the study and also for allowing them to conduct the experiment at MCFW nursery.

\section{References}

[1] G. S. Bhat and P. S. Chauhan, "Provenance variation in seed and seedling traits of Albizia lebbeck Benth," Journal of Tree Science, vol. 21, pp. 52-57, 2002.

[2] M. Faisal, P. P. Singh, and R. Irchhaiya, "Review on Albizia lebbeck a potent herbal drug," International Journal of Pharmaceutics, vol. 3, no. 5, pp. 63-68, 2012.

[3] D. Jøker, Seed Leaflet, Albizia lebbeck (L.) Benth, Danida Forest Seed Centre, Humlebaek, Denmark, 2000.

[4] H. P. Msanga, Seed Germination of Indigenous Trees in Tanzania, UBC Press, Vancouver, Canada, 2000.

[5] N. Khera and R. P. Singh, "Germination of some multipurpose tree species in five provenances in response to variation in light, temperature, substrate and water stress," Tropical Ecology, vol. 46, no. 2, pp. 203-217, 2005.

[6] M. Tigabu and P. C. Odén, "Effect of scarification, gibberellic acid and temperature on seed germination of two multipurpose Albizia species from Ethiopia," Seed Science and Technology, vol. 29, no. 1, pp. 11-20, 2001.

[7] R. W. Payne, D. A. Murray, S. A. Harding, D. B. Baird, and D. M. Soutar, GenStat for Windows Introduction, VSN International, Hemel Hempstead, UK, 13th edition, 2010.

[8] E. Khurana and J. S. Singh, "Germination and seedling growth of five tree species from tropical dry forest in relation to water stress: impact of seed size," Journal of Tropical Ecology, vol. 20, no. 4, pp. 385-396, 2004.
[9] W. F. Mwase and T. Mvula, "Effect of seed size and pre-treatment methods of Bauhinia thonningii Schum. on germination and seedling growth," African Journal of Biotechnology, vol. 10, no. 26, pp. 5143-5148, 2011.

[10] E. N. Chidumayo, "Growth responses of an African savanna tree, Bauhinia thonningii Schumacher, to defoliation, fire and climate," Trees, vol. 21, no. 2, pp. 231-238, 2007.

[11] D. Esen, O. Yildiz, M. Sarginci, and K. Isik, "Effects of different pretreatments on germination of Prunus serotina seed sources," Journal of Environmental Biology, vol. 28, no. 1, pp. 99-104, 2007.

[12] S. Azad, M. R. Manik, S. Hasan, and A. Matin, "Effect of different pre-sowing treatments on seed germination percentage and growth performance of Acacia auriculiformis," Journal of Forestry Research, vol. 22, no. 2, pp. 183-188, 2011.

[13] B. M. Khan, B. Koirala, and M. K. Hossian, "Effect of different pre-sowing treatments on germination and seedling growth attributes in Ghora Neem (Melia azedarach)," Malaysian Forest, vol. 64, no. 1, pp. 14-121, 2001.

[14] B. Koirala, M. K. Hossain, and M. S. Hossain, "Effects of different pre-sowing treatments on Adenanthera pavonia seeds and initial seedling development in the nursery," Malaysian Forest, vol. 63, no. 2, pp. 82-91, 2000.

[15] M. G. Likoswe, J. P. Njoloma, W. F. Mwase, and C. Z. Chilima, "Effect of seed collection times and pretreatment methods on germination of Terminalia sericea Burch. ex DC," African Journal of Biotechnology, vol. 7, no. 16, pp. 2840-2846, 2008.

[16] B. E. Ayisire, L. A. Akinro, and S. O. Amoo, "Seed germination and in vitro propagation of Piliostigma thonningii-an important medicinal plant," African Journal of Biotechnology, vol. 8, no. 3, pp. 401-404, 2009.

[17] M. Alamgir and M. K. Hossain, "Effect of pre-sowing treatments on germination and initial seedling development of Albizia saman in the nursery," Journal of Forestry Research, vol. 16, no. 3, pp. 200-2204, 2005.

[18] M. S. Azad, N. K. Paul, and M. A. Matin, "Do pre-sowing treatments affect seed germination in Albizia richardiana and Lagerstroemia speciosa?" Frontiers of Agriculture in China, vol. 4, no. 2, pp. 181-184, 2010.

[19] M. S. Azad, R. K. Biswas, and M. A. Matin, "Seed germination of Albizia procera (Roxb.) Benth. in Bangladesh: a basis for seed source variation and pre-sowing treatment effect," Forestry Studies in China, vol. 14, no. 2, pp. 124-1130, 2012.

[20] T. Merou, I. Takos, E. Konstantinidou, S. Galatsidas, and G. Varsamis, "Effect of different pretreatment methods on germination of Albizia julibrissin seeds," Seed Science and Technology, vol. 39, no. 1, pp. 248-252, 2011.

[21] M. S. Azad, M. Zedan-Al-Musa, and M. A. Matin, "Effects of pre-sowing treatments on seed germination of Melia azedarach," Journal of Forestry Research, vol. 21, no. 2, pp. 193196, 2010

[22] L. Schmidt, Dormancy and Pre-Treatment. Guide To Handling of Tropical and subTropical Forest Seeds, Danida Forest Seed Centre, Humlebaek, Denmark, 2000.

[23] B. M. Khan, B. Koirala, and M. K. Hossian, "Effect of different pre-sowing treatments on germination and seedling growth attributes in Ghora Neem (Melia azedarachL.)," Malaysian Forest, vol. 64, no. 1, pp. 14-121, 2001.

[24] F. O. Jimoh and A. T. Oladiji, "Preliminary studies on Piliostigma thonningii seeds: proximate analysis, mineral composition and phytochemical screening," African Journal of Biotechnology, vol. 4, no. 12, pp. 1439-1442, 2005. 

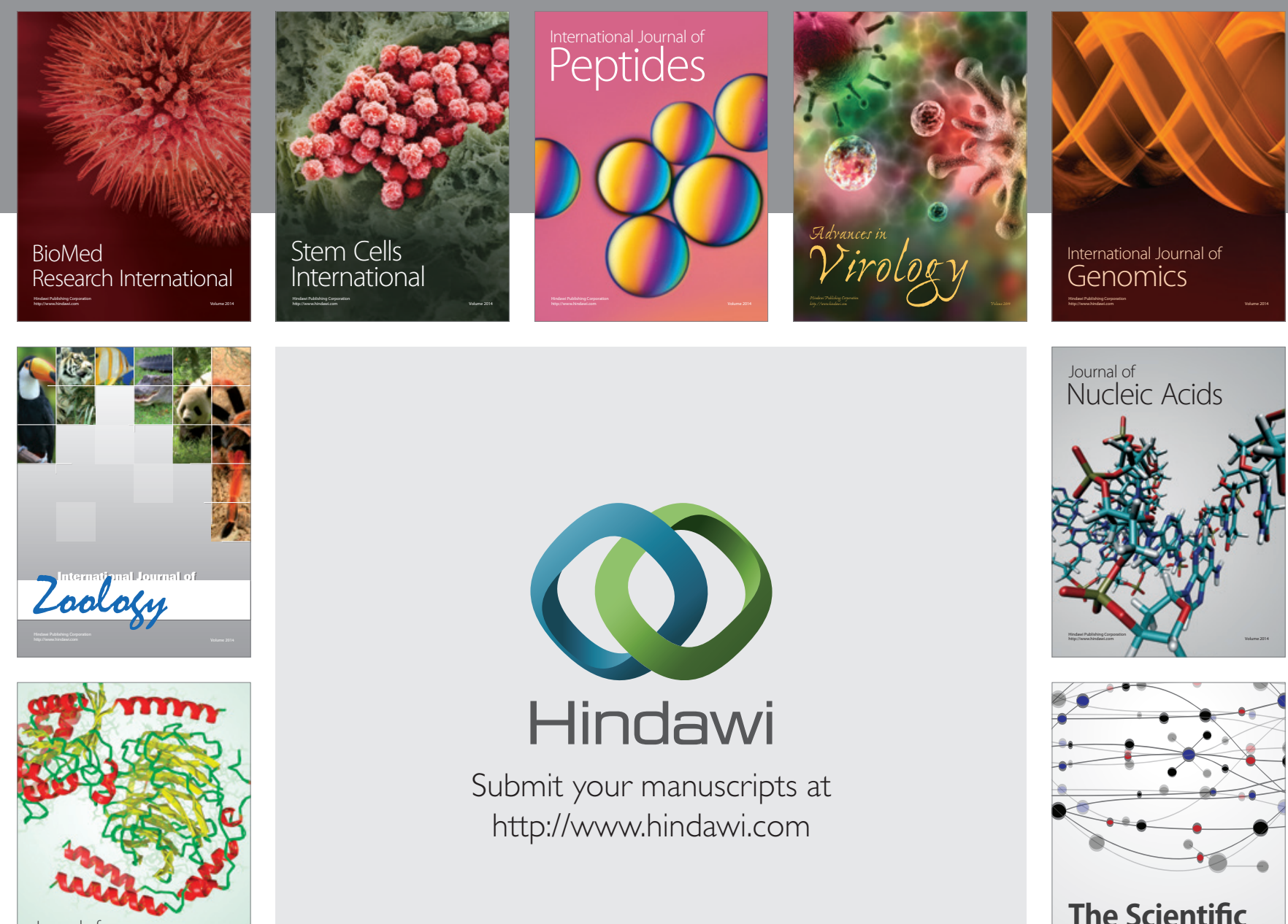

Submit your manuscripts at

http://www.hindawi.com

Journal of
Signal Transduction
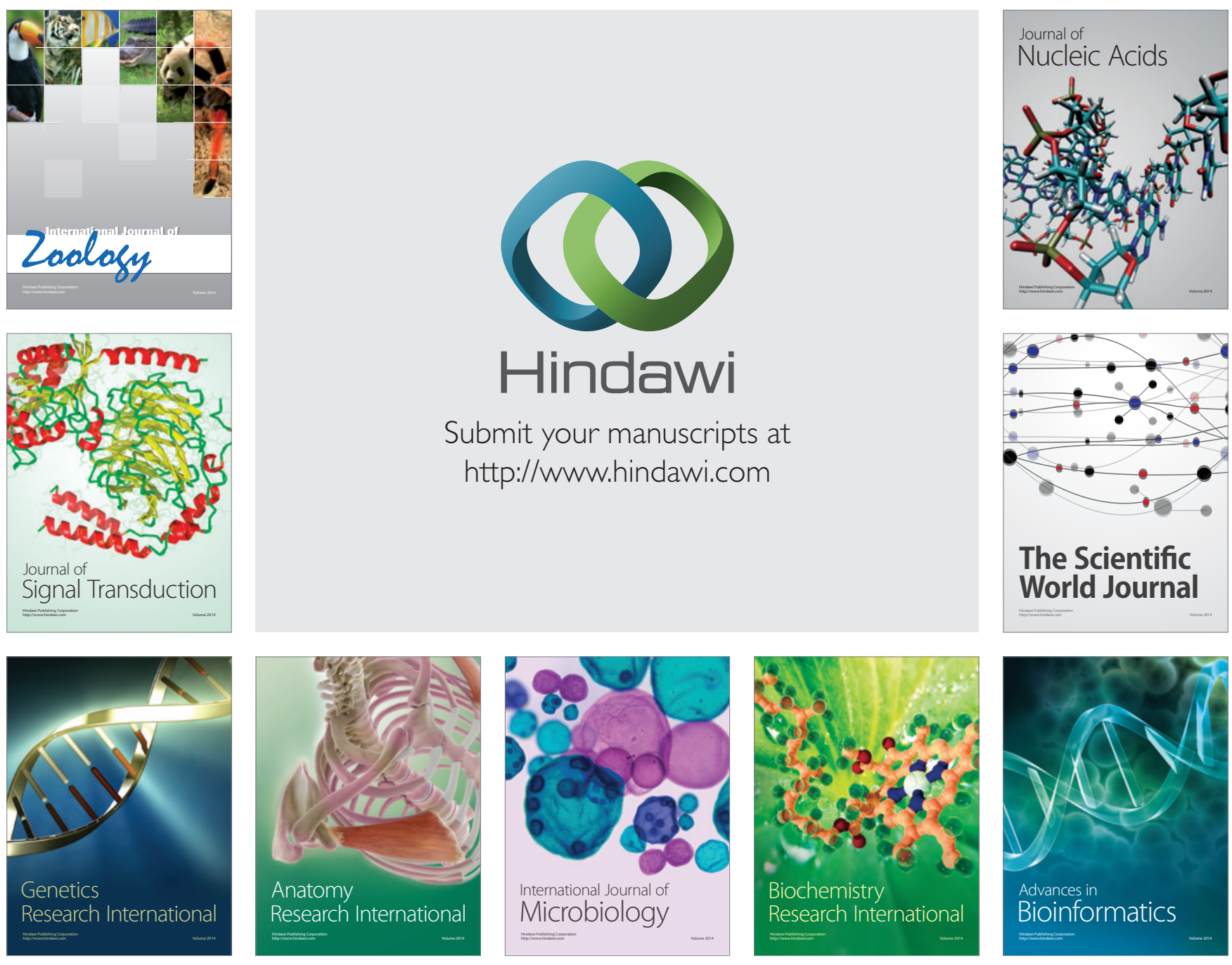

The Scientific World Journal
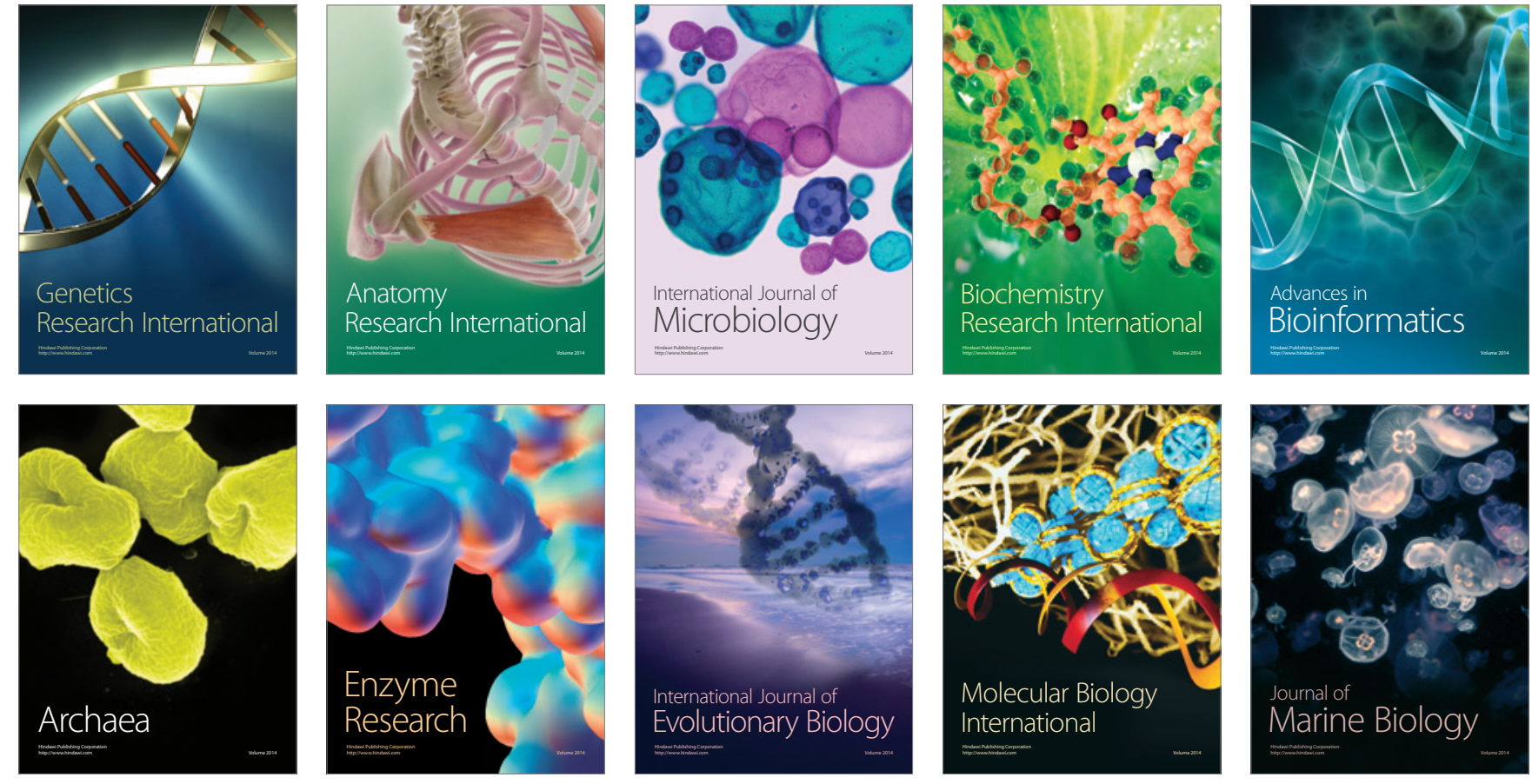